\title{
Alianças estratégicas e redes de associativismo em pequenos mercados varejistas
}

\author{
Daniel Paiva Mendes \\ Rute Kenneds Fernandes Queiroz \\ Roberta Dutra de Andrade \\ Elda Fontinele Tahim
}

Mestrando em Administração. Universidade Estadual do Ceará (UECE) Brasil - daniel.pamendes@gmail.com Graduação em Administração. Centro Universitário Católica de Quixadá (UNICATÓLICA) Brasil - rutekenneds@outlook.com Mestranda em Administração. Universidade Estadual do Ceará (UECE) Brasil - robertadutraandrade@gmail.com Doutora em Ciências Econômicas. Universidade Estadual do Ceará (UECE) Brasil - fontineletahim@gmail.com

\begin{abstract}
RESUMO
Este artigo tem por objetivo identificar os diferenciais competitivos e cooperativos adotados por uma rede de pequenos mercados varejistas, que encontraram no associativismo uma forma de se manter competitivos no mercado atual. As alianças estratégicas e redes de associativismo são alternativas para os pequenos empresários varejistas desenvolverem estratégias mais competitivas em relação aos seus concorrentes e também sobrevivem à chegada das grandes redes desse segmento. A rede de pequenos mercados se uniu em prol de objetivos comuns de proporcionar a seus participantes uma maior competitividade de mercado, como a possibilidade de aumentar o seu mix de produtos, redução de custos logísticos, maior poder de barganha com fornecedores, inserção de novas tecnologias no negócio, reformular estratégias para garantir o fortalecimento e produzir recursos que possam ser investidos em suas competências básicas. A pesquisa foi realizada em nove, das doze empresas associadas à rede, em quatro cidades. Uma contribuição importante desse estudo é o fato de que as experiências da rede de empresas analisada trouxeram ganhos significativos para a sobrevivência das organizações participantes e o fortalecimento da marca da rede, mediante de oportunidade única de cooperação estratégica.
\end{abstract}

Palavras-chave: Alianças estratégicas. Diferenciais competitivos. Cooperação Estratégica.

\section{Strategic alliances and networks of associations in small retail markets}

\begin{abstract}
This article aims to identify the competitive and cooperative specificities adopted by a small retailers' network, who found in associations a way to keep competitive in the current market. Strategic alliances and associative networks have been seen as an alternative for small retailers to increase strategic policies against competitors and the arrival of big players in same market. The small retail network market studied in this article united in favor of same objectives to provide its participants with a greater market competitiveness, such as mix of products, growth possibility, logistics cost reduction, greater bargaining power with suppliers, new technologies insertion in company, strategy reformulation to guarantee the strengthening of the enterprise and the production of resources to be invested in its basic competences. The research was conducted in nine of the twelve companies associated to retailers' network in four different cities. An important contribution of this study is that network of associations has brought significant gains for the survival of the associated companies as well as the strengthening of the network brand through strategic cooperation.
\end{abstract}

Keywords: Strategic alliances. Competitive specificities. Strategic cooperation. 


\section{INTRODUÇÃO}

Nos últimos anos, um ambiente de profundas transformações econômicas, políticas, socioculturais, tecnológicas e de intensivo crescimento da concorrência, criou um cenário de instabilidade para as organizações, em particular as pequenas e médias. Essas mudanças deixam evidente a necessidade de se estabelecer estratégias para que tais organizações se tornem eficientes, flexíveis e possam se manter competitivas e em posicionamento vantajoso no mercado (OLIVEIRA, 2012).

Neste cenário, as alianças estratégicas, parcerias, redes distintas de empresas e outras modalidades de cooperação se tornaram cada vez mais frequentes no meio empresarial, uma vez que as empresas reforçam o poder coletivo e a complementaridade de capacitações, na busca de inovação e vantagens competitivas, por meio destas parcerias e alianças, que se intensificam à medida que os mercados se abrem aos investimentos estrangeiros, criando uma nova ordem econômica que deu origem a um ambiente de competição muito acirrado.

O tema cooperação interorganizacional na configuração de rede e alianças estratégias é discutido nos meios empresarial e acadêmico tendo como ponto de partida os trabalhos de Thorelli (1986), Nohria (1992), Jarillo (1998), Lorange e Ross (1996), Amato Neto (2000), Verschoore (2004), Britto (2013), entre outros autores. Todos destacam a importância da cooperação interorganizacional como solução adotada, principalmente, pelas pequenas e médias empresas com vista à sobrevivência ou como mecanismo que uniformiza ações que possibilitem ganhos de escala e, consequentemente, competitividade, especialmente, em relação às grandes empresas.

As empresas de pequeno e médio porte estão predominando o mercado em quase todos os segmentos, entretanto, estas, normalmente, enfrentam maiores dificuldades de competição, dadas as suas limitações em termos de recursos e capacitação tecnológica. Corroborando esse fato, Sousa e Leone (2010, p. 90) argumentam que "os micro e pequenos negócios, em geral, não conseguem efetuar suas compras a preços justos e competitivos", incorrendo em aumento de custos que podem comprometer os resultados da empresa e ainda que "[....] enfrentam grandes dificuldades para se tornarem mais competitivos no mercado", resultando em altos índices de mortalidade precoce dessas empresas. A literatura acadêmica que trata do tema, entretanto, tem mostrado que a organização em rede ou aliança estratégica dessas empresas, entre outras vantagens, a redução de custos, a manutenção da flexibilidade e agilidade, bem como permite o fortalecimento da cadeia de valor e a garantia de espaço no mercado global.

No Brasil, um dos setores que mais utilizam esta estratégia de redes é o supermercadista, que se estruturou desde os anos de 90, a fim de enfrentar as ameaças advindas da implantação de grandes supermercados e da entrada de empresas estrangeiras. Desde então, essa modalidade de parcerias e a criação de alianças estratégicas que resultam no associativismo em rede ganha espaço e se amplia a cada dia, como um fator de competitividade e geração de emprego e renda (XAVIER; ANDION, 2010).

As associações em redes de supermercados iniciaram nas grandes cidades e ultimamente se estendem para cidades menores, em que pequenos supermercados e mercadinhos se unem, criando alianças estratégias no formato de redes de associativismo como o que está acontecendo no Estado do Ceará onde se observa sua interiorização. Esse fato é pouco explorado na literatura acadêmica, considerando ainda que é importante determinar o que levam estas empresas a se associarem em rede, uma vez que elas concorrem localmente.

Por outro lado, em decorrência da complexidade do mercado, as empresas vivem uma realidade de cooperação e competição, adotando, assim, estratégia cooperativa e/ou competitiva. As estratégias cooperativas são alianças interorganizacionais na busca de um objetivo comum, podendo envolver fornecedores, compradores e empresas cujos resultados beneficiam a todos. O objetivo de ingressar em uma aliança estratégica é variado entre os parceiros, por permitir, por exemplo, compra conjunta, uso da capacidade ociosa, rapidez e eficiência nos processos, acesso a mercado e até venda em conjunto (WINCKLER; MOLINARI, 2011). Dependendo, contudo, das alianças, as estratégias podem estar voltadas para a competição. Para Silva (2015, p. 144), as empresas podem também definir estratégias competitivas e colaborativas simultaneamente, "visto que o locus das competências distintivas não está mais na empresa de forma isolada, mas em toda a sua rede de relacionamentos".

A estratégia competitiva, geralmente, demanda uma posição que seja vantajosa e ao mesmo tempo sustentável de uma empresa em relação aos concorrentes ou a descoberta de posições no setor cujas forças competitivas sejam menos vulneráveis (PORTER, 1989). O autor aponta ainda que a empresa deve se defender de cinco forças competitivas básicas, chamadas de "forças competitivas de Porter" (entrantes potenciais, fornecedores, compradores, substitutos e concorrentes na indústria). Para entender tanto a estratégia de cooperação como a de 
competição, é necessário compreender a origem do comportamento cooperativo e competitivo bem como suas consequências em um ambiente de negócio.

Portanto, as questões norteadoras dessa pesquisa são: quais são os diferenciais competitivos e cooperativos de uma rede de empresa de varejo à luz das estratégias de Porter? A partir desse contexto, a pesquisa tem por objetivo identificar os diferenciais competitivos e cooperativos adotados por uma rede de pequenos mercados varejistas.

Para tal, o artigo está estruturado em cinco seções, incluindo a introdução. A segunda seção trata da revisão de literatura teórica sobre redes, suas caraterísticas e os ganhos deste tipo de estrutura bem com os principais fundamentos das estratégias de Porter. A seção seguinte traz a metodologia desenvolvida no estudo, ao passo que a quarta seção faz a análise dos resultados e principais discussões sobre o tema e, por fim, vêm as conclusões e suas implicações.

\section{REVISÃO DA LITERATURA}

A seguir serão sintetizados os principais elementos teóricos relacionados a alianças estratégicas e rede de empresas, as estratégias e forças competitivas de Porter e suas relevâncias para a competitividades das empresas. Além de aspectos relacionados à cadeia de valor e ao associativismo no setor de varejo de alimentos, com o intuito dar sustentação à análise proposta nessa pesquisa.

\subsection{Alianças estratégicas e redes de empresa}

Na visão de Mañas e Pacanham (2004), a aliança estratégica é caracterizada pela união de duas ou mais empresas com objetivo comum, sendo que cada qual aplica competências individuais com o intuito de se fortalecerem dentro do mercado. A aliança estratégica pode aumentar a responsabilidade e a confiança recíproca entre as partes envolvidas, à medida que uma empresa começa a se envolver de modo tímido e com o decorrer do tempo a cooperação entre organizações se fortalece (SOUSA; LEONE, 2010). Na formação de alianças em rede de varejo existem elementos decisivos para o sucesso das estratégias formuladas, pois o convívio de vários agentes estratégicos que compõem a cadeia de valor, influencia as fontes de informações sobre oportunidades e ameaças, ajudando a articular as tomadas de decisão com maior segurança (TAUHATA; MACEDO-SOARES, 2004).

De acordo com Klein et al. (2012), o nível de maturidade dos relacionamentos influencia na evolução de um grupo e a aliança entre as partes envolvidas é a conexão que deve ser mantida entre os associados, pois, caso esse vínculo deixe de existir, o grupo tende a acabar. Ainda na visão desses autores, o fator essencial dessa cooperação é a confiança mútua entre associados, fornecedores e clientes.

Para Lewis (1992), as alianças estratégicas podem proporcionar uma variedade de recursos que uma empresa isolada não consegue oferecer. Além disso, elas têm a capacidade de expandir a criação de produtos, diminuir os custos, inserir novas tecnologias e ainda reformular estratégias que garantam o seu fortalecimento, produzindo recursos que possam ser investidos em suas competências básicas. Assim, as empresas cooperam em prol de necessidades mútuas e partilham riscos para atingir um propósito comum.

As transformações no setor do varejo alimentício estão acontecendo com uma agilidade cada vez maior, e as empresas precisam inovar para sobreviver. O sucesso dos pequenos supermercados, muitas vezes, está fora de suas fronteiras, como na formação de alianças, que, em um ambiente econômico e competitivo, pode se tornar uma resposta adequada ante as mudanças provindas da evolução tecnológica (MENDEL; FERREIRA, 2006). Ainda na visão desses autores existem diversos motivos para os pequenos mercados construírem alianças, dentre as quais se destacam: os novos recursos de aprendizagem, o conhecimento, a redução de custo e o posicionamento estratégico nos quais as empresas situam novas práticas para aumentar as vantagens competitivas. Da mesma forma, Sousa e Leone (2010) ressaltam que as alianças têm papel fundamental na redistribuição de ativos intangíveis como habilidades e conhecimentos, o que implica em saber escolher os parceiros para evitar dificuldades de relacionamento. Além disso, para esses autores "o modelo ideal é aquele em que os objetivos, as habilidades e as competências se complementam" (SOUSA; LEONE, 2010, p. 95). 


\subsection{Estratégias e Forças Competitivas}

As estratégias competitivas são fundamentais para que as empresas tenham relevâncias no mercado, de maneira vantajosa, perante aos seus concorrentes, para isso é preciso que elas desenvolvam e implementem um conjunto de ações, planos e metas inovadores. Essas estratégias devem ser fruto de conhecimento aprofundado da estrutura da indústria, ou seja, da matriz de cinco forças competitivas de Michel Porter que são: 1. Novos entrantes, 2. Poder de barganha dos fornecedores, 3. Poder de barganha dos clientes, 4. Produtos substitutos e 5. Concorrentes (as quais serão discutidas na sequência) e, da forma que ela se modifica (BRASILEIRO; MORANDI, 2014).

Mañas e Pacanham (2004) apontam uma nova realidade que está sendo construída com a formação de alianças entre empresas concorrentes, que passam a ter elos de parcerias e começam a caminhar em conjunto, formulando novas estratégias para obter vantagens competitivas. Assim, elas se mantêm constantemente no mercado e alcançam melhores proveitos, como créditos, prazos e descontos oferecidos pelos fornecedores.

Para Mintzberg e Quinn (2001), a estratégia é definida como um plano que agrega as fundamentais metas, políticas e o conjunto de ações de uma organização de forma coesa. A formulação estratégica bem-sucedida contribui para ordenar os recursos de uma organização em uma atitude vantajosa. A vantagem competitiva que a empresa pode dispor é a diferenciação. Assim, Porter (1989) afirma que uma empresa se diferencia da concorrência quando oferece determinado evento especial e valioso para os compradores, além de proporcionar preço baixo.

Como apontam Mintzberg et al. (2007), é preciso ver as estratégias como plano, pretexto, padrão, posição e perspectiva, descritas e compreendidas da seguinte forma: como plano, a estratégia demonstra uma diretriz com a finalidade de alcançar os objetivos empresariais ou organizacionais; como pretexto, a estratégia é a manobra proposital para superar os concorrentes; a estratégia como padrão diz respeito aos critérios que existem nas ações realizadas; como posição, a estratégia é o ambiente interno- e externo - que envolve a empresa e, por fim, como perspectiva, a estratégia está ligada a maneira como a organização vê o mundo.

A estratégia aponta os caminhos a serem seguidos para se alcançar os objetivos almejados, sendo as estratégias genéricas classificações que permitem a escolha de estratégias específicas e diretas, nas quais a empresa procura alcançar o desempenho acima da média de mercado. Para obter vantagem competitiva, a empresa deve escolher que tipo de vantagem quer alcançar e considerar as estratégias genéricas de liderança em custo, diferenciação e enfoque de custo e diferenciação, conforme mostra a Figura 1.

A estratégia de liderança de custo envolve diretamente a expansão do mercado e visa a atingir o baixo custo, para que, assim, a empresa possa conquistar clientes sensíveis ao preço. A rentabilidade da empresa é influenciada por forças competitivas e liderança de custo. A liderança em custo é mais eficiente quando as empresas conseguem cortar custos ao mesmo tempo em que mantém os preços de mercado equivalentes aos dos concorrentes (MINTZBERG, 2007). Os custos mais baixos possibilitam o lucro, mesmo quando a concorrência é acirrada (PORTER, 1989; ROYER, 2010).

Figura 1 - As Estratégias Genéricas de Porter

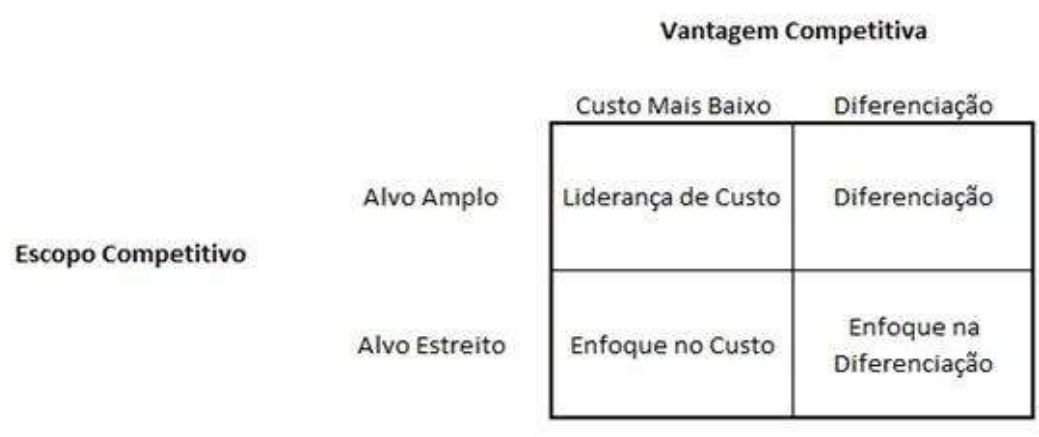

Fonte: Adaptado de Porter (1989, p. 10)

Na estratégia de diferenciação, a empresa busca destaque perante as ofertas dos seus concorrentes por meio dos seus atributos diferenciais competitivos, como, por exemplo, o atendimento personalizado ao cliente ou uma gama de produtos com preços variados, que os clientes estejam dispostos a pagar. O foco dessa estratégia é buscar retornos acima da média (PORTER,1989; ROYER, 2010). 
A estratégia de enfoque no custo, como a própria denominação sugere, diz respeito à amplitude do ambiente onde a organização procura unicamente a vantagem de custo em seu segmento-alvo. No enfoque na diferenciação, a empresa busca se distinguir em seus grupos-alvo. As duas últimas abordagens estratégicas também buscam retornos acima da média para a empresa (PORTER, 1989; ROYER, 2010). Royer (2010) afirma, ainda, que empresas seguidoras das estratégias genéricas de Porter conseguem ter bons desempenhos, superam seus concorrentes e possuem vantagens competitivas, tendo, por fim, sucesso em suas operações.

Com relação às cinco forças competitivas, Porter (1989) demonstra como a entrada de novos competidores, a ameaça de substituição, o poder de negociação dos compradores, o poder de negociação dos fornecedores e a rivalidade entre as empresas existentes. Essas forças, em conjunto, definem as forças da concorrência de uma empresa e a sua rentabilidade. Esse mecanismo auxilia na identificação de novas estratégias e proporciona que uma empresa identifique suas dificuldades e coordene os fatores de concorrência da indústria, conforme apresentado na Figura 2.

Figura 2 - As Cinco Forças Competitivas de Porter

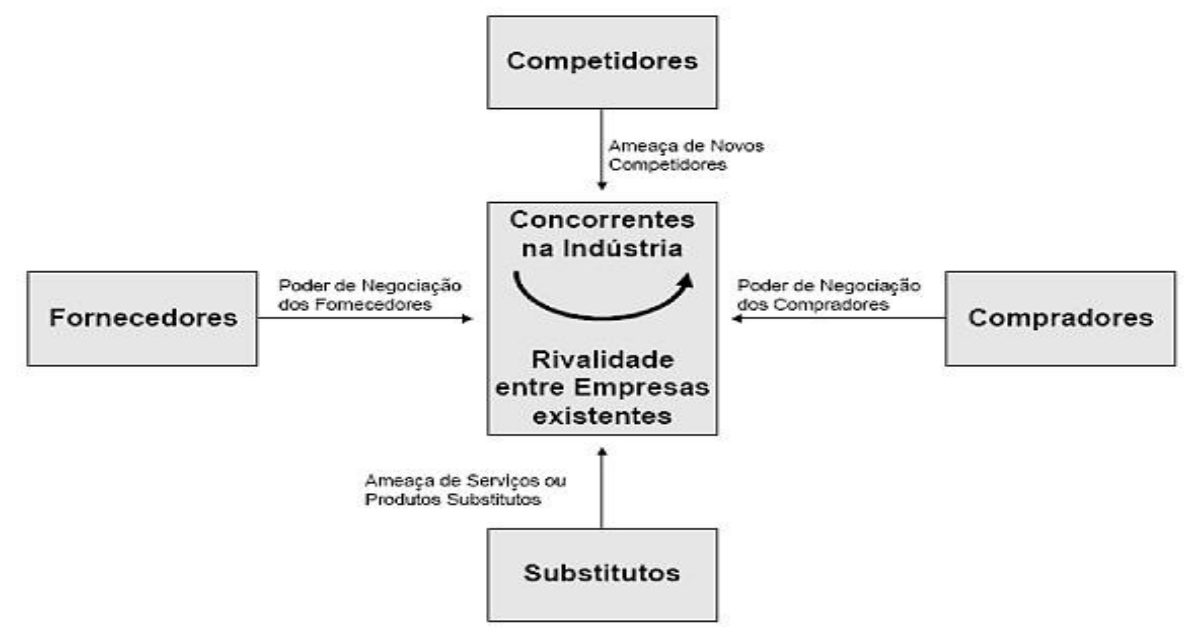

Fonte: Adaptada de Porter (1989, p. 4)

A matriz das cinco forças influencia a concorrência no ambiente de uma empresa, onde possa conhecer ela mesma e seus concorrentes. A ameaça da entrada de participantes no mercado e de produtos substitutos tentam manter o equilíbrio entre fornecedores e empresas, ocorrendo rivalidade, se tornando concorrentes. Nesse ponto, a rivalidade é crucial, para que essas empresas venham a atacar umas às outras ou criar elos e se unirem formando alianças como estratégia para permaneceram no mercado (MINTZBERG; AHLSTRAND; LAMPEL, 2009).

As estratégias competitivas devem ser fruto de conhecimento aprofundado da estrutura da indústria, ou seja, da matriz cinco forças e da maneira que ela se modifica (BRASILEIRO; MORANDI, 2014).

\subsection{Cadeia de Valor}

Para Porter (1989) a cadeia de valor de uma empresa é entendida como um conjunto de atividades executadas para projetar, produzir, comercializar, entregar e sustentar o seu produto. As modalidades como são exercidas individualmente essas atividades será o caminho para obter vantagem competitiva. A cadeia de valor separa as atividades de importância estratégica, para que se possa abranger o desempenho dos custos e os elementos existentes, bem como os potenciais de diferenciação. Dessa maneira, a empresa obtém vantagem competitiva ao executar atividades estrategicamente importantes de maneira econômica e superior à da concorrência (KLEIN et al., 2012).

Porter (1989) ressalta, ainda que as atividades de valor de uma empresa são física e tecnologicamente distintas, por meio das quais a indústria cria produtos valiosos para seus compradores. As atividades de valor são segmentadas em dois formatos gerais, atividades principais e de apoio. As principais estão relacionadas com a criação do produto, sua venda e o pós-venda. Subdividem em cinco categorias genérica, na parte inferior da cadeia, envolvendo a logística interna e externa, as operações, o marketing e o serviço. Enquanto as atividades de apoio são 
as que coordenam as atividades principais e a si mesmas, e estão divididas em quatro categorias: a infraestrutura da empresa, a gerência de recursos humanos, a aquisição e o desenvolvimento de tecnologia, às quais estão associadas as atividades principais e apoiam a cadeia interna, conforme identificado na Figura 3 (PORTER, 1989).

Para Silva, Barros e Claro (2014), a cadeia de valor é baseada em uma indústria ou o setor em que ela atua, mas cada empresa tem escopo de competitividade diferente da outra. A cadeia é uma ferramenta usada para identificação e intensificação das vantagens competitivas de uma organização.

Figura 3 - Cadeia de valor

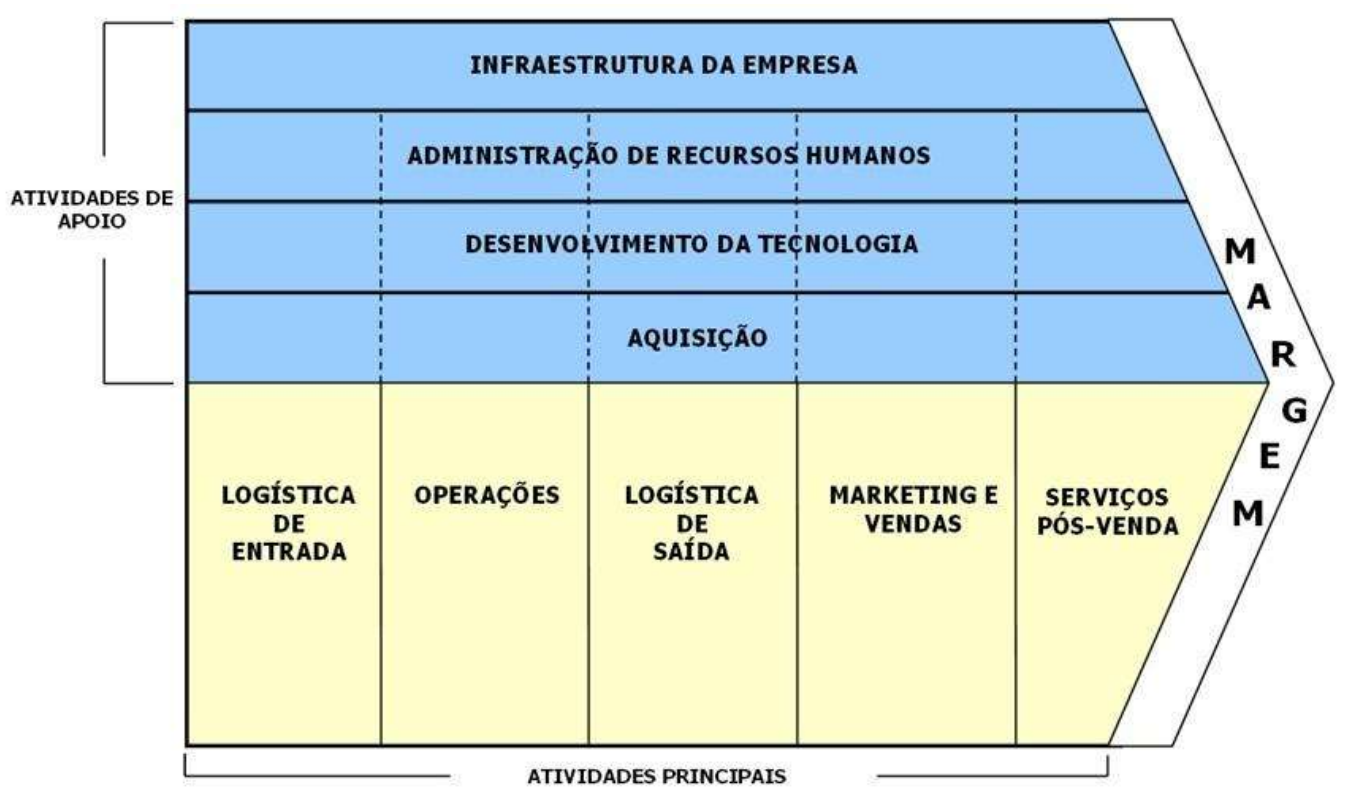

Fonte: Porter (1989, p. 32)

Os processos combinados em uma cadeia de valor devem ser classificados na função que enseja maior influência. É um sistema de atividades interdependentes e essas atividades são as que formam os elos na cadeia. Esses elos possibilitam vantagem competitiva com otimização ou coordenação. A capacidade de coordenar beneficia a empresa no sentido de redução de custos. Os mais conhecidos são os que estão entre atividades primárias e de apoio. Os elos podem surgir, possivelmente, pela mesma função, executada de maneira diferente e em razão dos custos reduzidos das atividades diretas por causa das indiretas (SILVA; BARROS; CLARO, 2014).

Nos estudos de Mintzberg, Ahlstrand e Lampel (2009) estes expressam a ideia de que as oportunidades de estratégias inovadoras não surgem de análises inférteis e do manuseio de números, seguem de experiências novas que podem criar oportunidades para novos discernimentos; ou seja, a competitividade advém de estratégias inovadoras de pessoas comprometidas, na intenção de fazer valer uma melhoria mútua.

\subsection{O Associativismo no Varejo de Alimentos}

Em todo o mundo, as pessoas sentem a necessidade de consumir. Compra-se por via dos canais de distribuição, que têm como objetivo suprir as necessidades do consumidor final, sendo o varejo o canal mais utilizado. Dessa forma, é possível caracterizar o varejo como segmentos de negócios que vendem produtos e serviços ao consumidor final, sendo a principal fonte de distribuição de alimentos e serviços em todo o mundo (LOPES et al., 2004).

Ainda segundo Lopes et al. (2004), grandes lojas de varejo, hipermercados e supermercados destacam-se e asseguram o seu espaço com um poder de competitividade, utilizando-se de estratégias de preços e marketing para conquistar clientes. Assim, os pequenos supermercados, principalmente os localizados em bairros e periferias, sentiram-se ameaçados com os novos entrantes. Tal motivo foi decisivo para os pequenos mercados varejistas unirem forças, organizados em associações comerciais, com empresas do mesmo segmento, para garantir sua sobrevivência e competitividade no mercado. 
No Brasil, o fenômeno do associativismo não é algo recente. A própria Confederação das Associações Comerciais e Empresariais do Brasil - CACB, tem suas origens nas associações comerciais de cada estado brasileiro, muitas delas nascidas ainda no Brasil-Colônia (CACB, 2017a). De acordo com a CACB, o associativismo é uma espécie de organização cuja finalidade é conseguir benefícios comuns para seus associados por meio de ações coletivas, e é uma ferramenta importante para fortalecimento das micro e pequenas empresas na busca por maior competitividade nos negócios, contribuindo com a ampliação de mercados, capacitação profissional, rede de contatos e gestão melhorada das empresas associadas (CACB, 2017b).

Efetivamente, o associativismo surge como alternativa de cooperação entre empresas, com o fortalecimento de laços e objetivos comuns (SCHMITT; MORETTO NETO, 2011). Na compreensão de Lopes et al. (2004), em razão das mudanças no varejo alimentar, os empresários de pequenos supermercados passam a unir-se, formando uma rede associativista, cujo foco de interesse grupal deve permanecer acima dos interesses individuais. Mañas e Pacanham (2004, p. 33) enxergam como principal dificuldade e desafio no associativismo a "dualidade entre competição e cooperação, onde é necessário um grande grau de discernimento dos gestores para perceberem que estratégias de cooperação podem ser mais benéficas do que as de competição".

Estudo realizado por Sousa e Leone (2010) revela que em uma rede de pequenos supermercados do Rio Grande do Norte, mostrou, por exemplo, que a união se deu por aspectos concorrenciais, poder de barganha junto aos seus fornecedores e a necessidade de melhor atendimento aos clientes, oferecendo melhores preços e serviços. Os autores apontam, entretanto, que não basta somente a integração à rede, pois esta não é suficiente para ensejar sobrevivência de nenhuma empresa. Tal integração tem de ser vista como estratégia complementar e não única na busca pela competitividade.

Na análise de Marqui, Guirro e Merlo (2004), as redes de negócios, inicialmente idealizadas com o objetivo de reduzirem os custos de aquisição de mercadorias, são porta de entrada para outras oportunidades e desenvolvimento de novas práticas gerenciais; melhoram a cultura empresarial de cada empresa pela troca de experiências entre os associados e proporcionam a inovação de layouts e, entre outros benefícios, tem destaque a vantagem competitiva adquirida com os ganhos em negociações, logística e distribuição.

No plano de ações conjuntas de uma rede, todos os aspectos são importantes, porém é possível destacar três fatores fundamentais que impulsionam a competitividades de pequenos supermercados de varejo: (i) plano de compras com o propósito de barganhar preços menores com os fornecedores; (ii) layouts das lojas e (iii) o marketing em conjunto. O SEBRAE (2016) confirma que a compra conjunta determina o poder de barganha com os fornecedores, pois estes reduzem preços e aumentam o prazo de pagamento, o que possibilita melhora da margem de lucro no preço final dos produtos.

Da mesma forma, Delalibera (2010) afirma a existência de vários motivos que influenciam a composição de grupos de compras ou rede, tais como: a aquisição de informações sobre potenciais fornecedores; a conquista de custos reduzidos, em razão do grande volume do pedido; a redução de gastos, em decorrência da economia de esforço e tempo na aquisição de produto; a qualidade no gerenciamento da cadeia de suprimentos que, por meio dessas negociações, permite a aquisição de produtos; a redução de riscos de abastecimento e dos custos logísticos, bem como o aprendizado mútuo. Todos esses fatores permitem que as empresas adquiram vantagens competitivas e que o associativismo seja a porta de entrada de um novo mix de produtos, parcerias e ampliação da parte física (layout).

Conforme destaca Kotler (1998), a influência do ambiente de uma loja atrapalha ou auxilia o processo de compra do cliente, portanto, o ambiente deve ser adequado para seu público-alvo, tornando-se uma oportunidade para diferenciação no mercado, visto que um layout é parte essencial na obtenção de uma máxima produtividade. Por intermédio de um ambiente bem elaborado, o consumidor sente-se confortável, feliz e estimulado, encontrando com facilidade os produtos oferecidos no espaço (CAMARGO; TOALDO; AREL SOBRINHO, 2009).

O marketing é uma ferramenta influente na divulgação, promoções e nos eventos das empresas associadas em rede, fortalecendo a marca e o posicionando no mercado Filho e Lepsch (2004) consideram o marketing como um meio de propagação de valor da empresa para seus clientes, tendo como principal foco a comunicação com o público-alvo e a consolidação da imagem e da marca. Nesse contexto, as estratégias devem ser formuladas de acordo com as ferramentas individuais do marketing, como publicidade, merchandising e promoções de vendas em forma estruturada.

Ainda segundo Andia Filho e Lepsch (2004), a criação da imagem da marca é vantajosa e favorável, visto que a associação de pequenos supermercados acaba por abrigar-se sob uma única bandeira, ensejando padrões, como a estabilização de fachadas, a comunicação visual interna, o layout e os materiais promocionais em comum, como 
panfletos, encartes e sacolas de compras com a marca da associação. A definição de imagem da marca é importante, pois torna a empresa conhecida entre os consumidores e enseja confiabilidade para a associação, ou seja, torna-se uma força motivadora para o comportamento do consumidor (LIMEIRA, 2003).

\section{METODOLOGIA}

O modelo teórico-metodológico adotado nessa pesquisa é de natureza qualitativa, com base em estudo de caso, realizado em uma rede de associação de pequenos supermercados, com sede na cidade de Quixadá (CE). Os objetivos da pesquisa nasceram em uma perspectiva descritiva, decorrente da concepção de Vergara (2014) que é de identificar os diferenciais competitivos e cooperativos adotados por uma rede de pequenos mercados varejistas.

A técnica de coleta de dados escolhida foi a entrevista em profundidade, baseada em roteiro ou semiestruturada. Na orientação de Pires (2008), as entrevistas absorvem as experiências de vida dos entrevistados e seus pontos de vista a respeito do funcionamento de uma instituição, dando conta dos sentimentos e percepções sobre as experiências vividas pelos sujeitos. O roteiro de entrevista é "caracterizado por uma preparação prévia, dando ao entrevistador flexibilidade para ordenar e formular as perguntas durante a entrevista" (GODOI; MATTOS, 2010, p. 304).

As entrevistas foram gravadas e transcritas, sendo realizada posteriormente a categorização da análise dos dados através do método de análise de conteúdo de Bardin (1979), contendo algumas adaptações de Minayo (2006). A categorização destacou as unidades de sentidos das falas dos entrevistados, buscando inferir os significados no contexto da fala, tentando ultrapassar a mera descrição da mensagem e assim atingir uma interpretação mais profunda (GOMES, 2010; MENDES, 2007; DELLAGNELO; SILVA, 2005).

A associação de mercadinhos está situada no sertão central cearense, com sede no Município de Quixadá. Atualmente, conta com um total de 12 associados em cidades circunvizinhas, tais como Quixeramobim, Senador Pompeu e Ibaretama. Na pesquisa de campo foram entrevistados nove associados dessa rede, no período de agosto a dezembro de 2016. O critério de julgamento utilizado para o encerramento da amostra qualitativa foi a saturação empírica. De acordo com o entendimento de Pires (2008) e Godoi e Mattos (2010, p. 309), a saturação empírica é identificada "à medida que vai vivenciando casos similares nas respostas dos entrevistados, e o pesquisador não encontra dados adicionais que possam contribuir para o desenvolvimento da pesquisa".

Após a análise, definição das unidades de contexto e categorização, na etapa de interpretação dos resultados, foi realizada a interpretação indicadores tratados, ou seja, o que eles revelaram. De acordo com Dellagnelo e Silva (2005, p. 113), a "interpretação envolve explicar achados, responder questões, anexar significância a resultados particulares e colocar padrões num quadro analítico". Nessa etapa foi possível alcançar o proposto pela análise de conteúdo.

O conhecimento teórico do pesquisador, com sua percepção, intuição e experiência a respeito do fenômeno em análise é o que contará para a interpretação (DELLAGNELO; SILVA, 2005). A fim de preservar o anonimato dos associados da rede, participantes da pesquisa, a todos os entrevistados foram atribuídos nomes fictícios, conforme identificado nos Quadros de Categorização de falas dos sujeitos.

\section{ANÁLISE E DISCUSSÃO DOS RESULTADOS}

A categorização exploratória das falas dos sujeitos no Quadro 1 resultou nos seguintes temas emergentes que estão ligados às estratégias de Porter, com base na matriz cinco forças e na estratégia genérica. As dimensões de fala das três primeiras categorias, expectativas e razões, Quadro 1, fazem parte da matriz cinco forças da rede. Está relacionada ao ambiente onde as empresas estão inseridas e como estas se encontram no seu posicionamento no mercado. Porter (1989) reforça a noção de que a matriz das cinco forças influencia a concorrência no ambiente de uma empresa, onde possa conhecer ela mesma e seus concorrentes. Como suporte, nessa teoria, foi percebido que todas as empresas que fazem alianças, na rede analisada, se engajam pelo mesmo motivo: as ameaças de atuarem sozinhas no mercado. Então, elas procuram se agrupar, como rede, com a finalidade de obter competitividade e sinergia com outras organizações do mesmo segmento e que buscam diferenciação no mercado.

A dimensão de fala do terceiro fator (categoria), que são os diferenciais está ligado à estratégia genérica. Porter (1989) ressalta que essas estratégias genéricas permitem enfatizar nas estratégias de custos e de diferenciação o escopo competitivo para serem atingidas no alvo amplo. Então, por meio das falas, foi possível observar que as 
empresas envolvidas em rede de associativismo buscam enxugar seus custos, melhores preços e promoções para seus consumidores-alvo.

Quadro 1 - Categorias de expectativa, razões e diferenciais.

\begin{tabular}{|c|c|}
\hline Categorias & Dimensão de Fala \\
\hline \multirow[t]{6}{*}{ Expectativas } & "Busca por informação de novas parcerias". Emilio \\
\hline & "Comprar e conseguir um preço mais acessível". Fernanda \\
\hline & "Me torna mais competitivo no mercado". Guto \\
\hline & "Melhorar o poder de barganha nas negociações com os fornecedores". Júlio \\
\hline & "Crescimento e fortalecimento, manter no mercado". Francisco \\
\hline & "Informações e ter o poder de compras". Val \\
\hline \multirow[t]{6}{*}{ Razões } & "Fortalecer a nossa marca". Emilio \\
\hline & "Ser parceiro acima de tudo e disseminar essa visão de parceria". Fernanda \\
\hline & "Estando em grupo passamos a ter benefícios e conhecimentos". Guto \\
\hline & "Flexibilidade de compras e produtos diferentes". Júlia \\
\hline & $\begin{array}{l}\text { "Convicção que juntos teremos um maior respaldo junto às instituições } \\
\text { governamentais, entidades de classe e também junto aos nossos fornecedores". Júlio. }\end{array}$ \\
\hline & $\begin{array}{l}\text { "Necessidade de fortalecimento, troca de informações, busca por crescimento, realizar } \\
\text { compra conjunta e fortalecimento da rede a cada dia". Francisco }\end{array}$ \\
\hline \multirow[t]{5}{*}{ Diferenciais } & "Preços a informação, acompanhando as tendências de mercado". Emilio \\
\hline & "Conhecer a necessidade do cliente e oferecer algo diferente na loja". Guto \\
\hline & "Foco é o atendimento ao cliente, ofertar promoção de produtos". Fernanda \\
\hline & "Produtos ofertados no encarte e as promoções". Júlia \\
\hline & "Diversidade de produtos, Mix adequado a realidade da nossa loja". Francisco \\
\hline
\end{tabular}

Fonte: Dados da pesquisa (2016).

A conexão entre os associados da rede acontece vantajosamente, pois eles possuem diversos fatores em comum, que evidenciam esse engajamento na rede, de modo estratégico, conforme identificado nas discussões de Guto - "estando na rede o deixa mais competitivo no mercado" - e Francisco, que ratifica a importância de ser um associado, fica, assim, mais acessível - "o crescimento, fortalecimento e manter" sua loja no mercado.

O Quadro 2, apresenta as falas dos temas emergentes, que são a negociação, o layout e o marketing. Os associados da rede têm a certeza de que negociar em conjunto é muito vantajoso para fortalecer a associação em vários aspectos, pois adquirem o maior respaldo durante as negociações com seus fornecedores, à medida que conseguem obter poder de barganha por intermédio dos volumes de compras. Com isso, os empresários oferecem em suas lojas preços mais atraentes com o mix variado de produtos nas gôndolas para os seus clientes.

Para Brasileiro e Morandi (2014), as condições que tornam os fornecedores poderosos são apreciadas com aqueles que tornam fortes compradores. O poder de barganha é influenciado pela quantidade de compradores com os volumes de compras que eles realizam. Se os fornecedores proporcionam pequenos diferenciais, melhorando os custos e a qualidade no atendimento são esses fatores essenciais para mantê-los como clientes.

A rede de associativismo tem o enfoque de reduzir os custos das compras durante as negociações. Emílio e Júlio garantem que os fornecedores oferecem maior credibilidade, confiança, preços e prazos diferenciados para todos os associados da rede. Francisco observa que esses fornecedores, depois que começaram a negociar por intermédio da rede, passaram a proporcionar condições diferenciadas. Caso, pois o empresário estivesse sozinho no mercado, jamais conseguiria essas condições, principalmente com os grandes fornecedores. Martim destaca que existem tabelas diferenciadas de preço para quem é associado à rede. Todos esses benefícios como de preço, prazo, variedade de produtos, acesso à informação e tecnologia, são fatores de vantagens competitivas oferecidas aos empresários, tornando a chave do crescimento e proporcionando a expansão dos seus negócios. 
Tais mudanças podem estar baseadas nas estratégias genéricas de Porter (1989), pois permitem a escolha de estratégias específicas e diretas, contribuindo, assim, para melhorar o desempenho e competitividade das pequenas empresas em rede de Quixadá. Na perspectiva de Oliveira (2004), as estratégias de Porter são relevantes para todas os arranjos organizacionais de uma empresa, pois requerem várias habilidades diferentes, o que permite a expansão e a adesão de novas formas de estratégias.

Os entrevistados Emilio e Fernanda descrevem que, depois de associados à rede, obtiveram informações sobre como organizar a área de vendas e produtos nas gôndolas, a importância do layout, principalmente com a automação fiscal em todos os check-outs do supermercado. Enquanto isso, Martim e Guto revelam que as suas lojas tiveram um influxo de mudanças muito grande, pois, ambas as lojas dobraram a sua área de vendas. As lojas associadas passaram a traçar estratégias padronizadas nas ações de marketing, fazendo um calendário promocional mensal com ofertas exclusivas em encarte, direcionado ao consumidor final. Todas as lojas hoje têm suas fachadas padronizadas com a marca da rede, juntamente com logomarca do associado.

Na compreensão de Limeira (2003), a fixação da imagem da marca é poderosa, pois, além de torná-la conhecida entre os consumidores, dá credibilidade para a Associação, funcionando como força motivadora do comportamento do consumidor. Todos os associados valorizam a marca da rede. $\mathrm{O}$ entrevistado Júlio esclarece que é de total importância sinalizar, comunicar para os clientes e fornecedores que são membros associados a uma rede, e garante que é fator diferencial nas negociações. Guto e Emílio complementam exprimindo que há várias lojas associadas na região do Sertão Central, sendo esta uma realidade importante, e mostra que a rede é competitiva e cresceu ao longo tempo.

Nessa pesquisa foi identificado o fato de que os fatores de competitividades de uma rede de associativismo de pequenos supermercados estão ligados às teorias de Porter. Por exemplo, o fato de a matriz cinco forças estar diretamente ligada ao ambiente e de como a empresa se reconhece no mercado. Esses empresários se sentiram ameaçados e uniram-se, ao perceberem que a atuação em rede favorece o desenvolvimento de estratégias competitivas e que seria inviável atuando isoladamente, como foi identificado na fala de Júlio "[...] conseguimos preços e prazos diferenciados" e Francisco "os fornecedores começam a nos enxergar de uma forma diferente [...]".

Os mercadinhos integrantes da rede têm estratégias competitivas identificadas na maneira como eles se posicionam no mercado e nas suas estratégias traçadas em conjunto. A diferenciação da rede, como, por exemplo, 0 poder de barganha com fornecedores na compra conjunta, proporciona uma redução de custos às empresas associadas, possibilitando a venda de seus produtos a preços mais acessíveis para seus consumidores.

Quadro 2 - Categorias de negociação, layoute marketing

\begin{tabular}{|c|c|}
\hline Categorias & Dimensão de Fala \\
\hline \multirow[t]{5}{*}{ Negociação } & "Fornecedores oferecem uma maior credibilidade e confiança". Emilio \\
\hline & "Atendimento diferenciado". Guto \\
\hline & "Conseguimos preços e prazos diferenciados". Júlio \\
\hline & $\begin{array}{l}\text { "Fornecedores começam a nos enxergar de uma forma diferente e com isso nos trouxe condições } \\
\text { diferenciadas". Francisco }\end{array}$ \\
\hline & "Existe até uma tabela diferenciada de preços para nós associados". Martim \\
\hline \multirow{8}{*}{ Layout } & $\begin{array}{l}\text { "Após associar começamos a ter informações sobre layout, organização das gôndolas e estrutura } \\
\text { da parte física e buscamos a perfeição". Emilio }\end{array}$ \\
\hline & $\begin{array}{l}\text { "Hoje temos o porte de mercadinho com frente de loja com caixas e sistema, estamos já bem". } \\
\text { Fernanda }\end{array}$ \\
\hline & $\begin{array}{l}\text { "Muitas mudanças como de organização e arrumação de mercadoria nas gôndolas e área de } \\
\text { vendas foi ampliado para o dobro". Guto }\end{array}$ \\
\hline & $\begin{array}{l}\text { "Só duplicou, antes a loja tinha } 100 \text { metros e hoje } 220 \text { metros e toda a parte de layout foi ampliada } \\
\text { para expor e sinalizar os produtos". Martim }\end{array}$ \\
\hline & $\begin{array}{l}\text { "A área de vendas cresceu com a estrutura para melhor servir os clientes, adequamos o layoute o } \\
\text { espaço físico ao público". Francisco }\end{array}$ \\
\hline & $\begin{array}{l}\text { "Dez anos de rede, a minha loja expandiu principalmente na parte física para poder expor melhor } \\
\text { os produtos, ficar mais visível para o cliente". Júlia }\end{array}$ \\
\hline & "Em parcerias com o Sebrae muitas mudanças aconteceram através das informações". Val \\
\hline & $\begin{array}{l}\text { "Com a logomarca da rede juntamente com a minha, mostra que somos associados à rede, e dá } \\
\text { maior credibilidade e confiança para os clientes". Emilio }\end{array}$ \\
\hline
\end{tabular}




\begin{tabular}{|l|l|}
\hline \multirow{3}{*}{ Marketing } & "Existem várias lojas espalhadas na cidade e isso dá uma imagem de força". Guto \\
\cline { 2 - 3 } & "Maneira de divulgar que somos associados à rede". Júlia \\
\cline { 2 - 3 } & $\begin{array}{l}\text { "Fundamental importância sinalizar, comunicar para os clientes e fornecedores que somos da } \\
\text { rede". Júlio }\end{array}$ \\
\cline { 2 - 2 } & "Dar uma imagem de grande e boa imagem para o cliente". Martim \\
\hline
\end{tabular}

Fonte: Dados da pesquisa (2016).

O enfoque de diferenciação acontece além das promoções nas gôndolas nos pequenos mercados. Essa diferenciação também pode ser vista como um serviço adicional que a empresa oferece a seus consumidores, que antes não era oferecido, conforme destacado na fala de Emílio "preços a informação, acompanhando as tendências de mercado" e Guto "conhecer a necessidade do cliente e oferecer algo diferente na loja".

A cadeia de valor das empresas associadas é modificada após a atuação em rede. As empresas passaram a fazer negociações em conjunto, oferecendo um mix de produtos diferenciados em perfumaria, limpeza, frutas, hortaliças, verduras, frios em geral, serviços de entregas, sorteios e brindes. Com essas ações, as empresas associadas começam a ter competitividade e passam a vender maior volume, atendendo as necessidades dos seus consumidores. Essas ações foram importantes para os mercados varejistas ampliarem suas lojas nas partes físicas e agregarem mais produtos em suas gôndolas.

Outro fator importante a ser destacado dentro da cadeia de valor são as ações de marketing. Antes de serem associados à rede, os mercadinhos tinham pouca ou nenhuma experiência em ações de marketing, nem mesmo uma fachada de loja, que na visão do empresário Júlio, é de "fundamental importância sinalizar, comunicar para os clientes e fornecedores que somos da rede". Essas estratégias trouxeram resultado para as empresas associadas, ao trabalharem o nome da rede juntamente com a logomarca da empresa, nas fachadas das lojas, como estratégia de fortalecer a marca da rede e empresa associada, conforme identificado na fala de Martim [...] dar uma imagem de grande (...) e boa imagem para o cliente". Mañas e Pacanham (2004, p. 32) alertam para a ideia de que o "mais importante para o sucesso desse tipo de disposição organizacional é a integração de metas e objetivos [...] que constituírem efetivamente uma rede".

A rede de empresa pesquisada tem caraterísticas bem peculiares e diferente das experiências identificadas por Xavier e Andion (2010), Mañas e Pacanham (2004), Marqui, Guirro e Merlo (2004). As empresas que fundaram a rede eram antes classificadas como bodegas, ou seja, uma miniempresa com muitas limitações no seus produtos e serviços, sem autosserviço adequado. Além disto, todas elas tinham características muito semelhantes, tais como; localizadas no Sertão Central cearense; escassez de recursos para investimentos, linhas de crédito limitado para investimentos, baixa escolaridade dos empresários e ausência de apoio interorganizacional.

\section{CONCLUSÃO}

O mercado está cada vez mais competitivo, e a estratégia é o fator determinante para que empresas se mantenham ativas em posição competitiva com o mercado. Este ensaio integra um estudo sobre os diferenciais competitivos de uma rede de associativismo de pequenos mercados varejistas, que formaram alianças com outras empresas do mesmo segmento para se manterem ativos no mercado.

As organizações do varejo alimentício que antes delimitadas, ou seja, pequenos negócios classificados como bodegas, com o decorrer dessa estruturação interorganizacional passaram a ser pequenos mercados varejistas, oferecendo um novo conceito por intermédio das transformações e da valorização na área de vendas, bem como ampliação de suas lojas, investindo e layout e no espaço físico das gôndolas para expor os produtos e aquisição de equipamentos como maquinários para frios e tecnologias.

Durante a pesquisa foi identificado o fato de que os associados percebem que as negociações em rede trazem condição mais vantajosa para suas empresas. As empresas varejistas associadas tornaram-se mais competitivas na precificação de seus produtos, com um mix mais atraente, o que proporcionou a maior lucratividade e, por consequência, elas expandiram suas infraestruturas e o marketing.

As empresas, por meio do uso de compra conjunta, conseguiram barganhar preços, ter prazo diferenciado, maior variedade de produtos, principalmente em perfumaria, limpeza, frutas, verduras e frios em geral, proporcionando aos clientes uma comodidade. Praticamente todos os varejistas associados à rede ampliaram a estrutura física e tecnológica de suas lojas, com investimentos em layout e compra de equipamentos, para atender 
essa demanda de novo mix de produtos. Também investiram em treinamentos para os seus colaboradores para garantir o melhor atendimento aos seus consumidores. Assim, as forças competitivas de Porter e cadeia de valor são de grande relevância para as empresas que têm a intenção ou que já estejam engajadas em rede de associativismo, pois essas teorias fundamentam a necessidade de estar engajados em grupos e as vantagens de terem estratégias definidas e compartilhadas por todos da rede. Mañas e Pacanham (2004, p. 32) já citavam a importância de compartilhar "alguns elementos de suas cadeias de valor", mas as empresas devem estabelecer "relações mais superficiais, mantendo suas identidades individuais e buscando estabelecer vantagens competitivas apenas em determinados pontos desta cadeia".

Espera-se que as experiências em rede dos pequenos mercados varejistas de alimentos analisadas possam servir como inspiração para outros empresários adotarem estratégias semelhantes ante a necessidade de se manter competitivo na realidade atual. Isto porque, está comprovado, em vários estudos empíricos sobre cooperação, rede de associativismo e outras parcerias estratégias de empresas, que esses tipos de relacionamentos só trazem benefícios para as empresas participantes. Esse fato também é comprovado nesse estudo quando, se conclui que as experiências da rede de empresas analisadas trouxeram ganhos significativos para sua sobrevivência e fortalecimento da marca da rede, por meio de oportunidade única de cooperação estratégica entre os participantes. Percebeu-se, ainda, que os associados tiveram o poder de reinventar e constituir oportunidades de crescimento para suas empresas situadas no Município de Quixadá e cidades circunvizinhas, que resultaram na geração de emprego e renda para os municípios.

\section{REFERÊNCIAS}

\section{AMATO NETO, J. Redes de cooperação produtiva e clusters regionais oportunidades para as pequenas e} médias empresas. São Paulo: Atlas, 2000.

ANDIA FILHO. L.; LEPSCH. S. L. Comunicação de marketing em rede de pequenos supermercados: Um estudo de caso na associação regional de supermercados do interior de estado de São Paulo. REA - Revista Eletrônica da Administração, v. 3, n. 1, p. 1-9, 2004.

BARDIN, L. Análise de Conteúdo. Lisboa: Ed. 70, 1979.

BRASILEIRO, A.F.; MORANDI, T.A. As forças e estratégias de Michael Porter no ramo audiovisual: estudo de caso de uma produtora São João Del-Rei (MG). Revista Iniciacom, v. 6, n. 1, p. 1-12, 2014.

BRITTO, J. N. P. Cooperação interindustrial e redes de empresas. In: KUPFER, David; HASENCLEVER, Lia (Org.). Economia industrial: Fundamentos teóricos e práticos no Brasil. 2. ed. Rio de Janeiro: Editora Campus, 2013. p. 211-230.

CACB. CONFEDERAÇÃO DAS ASSOCIAÇÕES COMERCIAIS E EMPRESARIAIS DO BRASIL. É do Brasil. [2017a]. Disponível em: <http://cacb.org.br/sobre-a-cacb/historia>. Acesso em: 22 ago. 2017.

. Associativismo para desenvolver o negócio. [2017b]. Disponível em: <http://cacb.org.br >. Acesso em: 22 ago. 2017.

CAMARGO, S. M.; TOALDO. A. M. M.; AREL SOBRINHO, Z. O layout como ferramenta de marketing no varejo. In: ENCONTRO NACIONAL DE PÓS-GRADUAÇÃO EM ADMINISTRAÇÃO, 33., 2009, São Paulo. Anais... São Paulo, SP: ANPAD, 2009. p. 1-16.

DELALIBERA. P. H. A. Modelos de compras conjuntas adotados em arranjos Inter organizacionais: pesquisa levantamento no estado de Minas Gerais. 2010. Dissertação Mestrado (Mestre em Ciências em Engenharia de Produção) - Universidade Federal de Itajubá, Itajubá, 2010.

DELLAGNELO, E.H.L.; SILVA, R. C. Análise de conteúdo e sua aplicação em pesquisa na administração. In.: VIEIRA, M.M.F; ZOUAIN, D. M. (Org.). Pesquisa Qualitativa em administração: teoria e prática. Rio de Janeiro: Fundação Getúlio Vargas, 2005. p.97-108.

GODOI, C. K.; MATTOS, P. L. C. L. Entrevista qualitativa: instrumento de pesquisa e evento dialógico. In: GODOI, C. K.; BANDEIRA-DE-MELLO, R.; SILVA, A. (Org.). A pesquisa qualitativa em estudos organizacionais: paradigmas, 
GOMES, R. Análise e interpretação de dados de pesquisa qualitativa. In: MINAYO, M.C.S; DESLANDES, S. F.; GOMES, R. Pesquisa social: teoria, método e criatividade. 29. ed. Petrópolis, RJ: Vozes, 2010. p. 79-108.

JARILLO, J. Carlos. On Strategic Networks. Strategic Management Journal, [S. I.], v. 9, p. 31-41, 1998.

KLEIN, D. B. et al. Alianças estratégicas como forma de obter vantagem competitiva: um estudo teórico sobre o tema. In: SIMPÓSIO DE EXCELÊNCIA EM GESTÃO E TECNOLOGIA, 9., 2012, Maceió. Anais... Maceió, AL: AEDB, 2012. p.1-9.

KOTLER, P. Administração de Marketing: Análise, Planejamento, Implementação e Controle. 5. ed. São Paulo: Atlas, 1998.

LEWIS, J. Alianças Estratégicas: estruturando e administrando parcerias para o aumento da lucratividade. São Paulo: Pioneira, 1992.

LIMEIRA, T. M. V. Administração das comunicações de marketing. Gestão em Marketing. São Paulo: Saraiva, 2003.

LOPES, F. F. et al. Estratégias de rede de empresa: o associativismo no pequeno varejo alimentar. In: SEMINÁRIO DE ADMINISTRAÇÃO PPGA/FEA/USP, 7., 2004, São Paulo. Anais... São Paulo, SP: USP, 2004. p. 1-15.

LORANGE; P.; ROSS, J. Aliança Estratégicas: formulação, implementação e evolução. São Paulo: Atlas, 1996.

MAÑAS, A. V.; PACANHAN, M. N. Alianças estratégicas e redes associativistas como fonte de vantagem competitiva no varejo de material de construção. Revista Brasileira de Gestão de Negócios, São Paulo, n. 14, p. 19-32, 2004.

MENDEL, P. R.; FERREIRA, G. C. A gestão de Alianças estratégicas como base para a inovação tecnológica: o caso de uma empresa petroquímica. In: SIMPÓSIO DE GESTÃO DA INOVAÇÃO TECNOLÓGICA, 24., 2006, Gramado.

Anais... Gramado, RS: ANPAD, 2006. p.1-17.

MENDES, A. M. Pesquisa em psicodinâmica: a clínica do trabalho. In: MENDES, A. M. (Org.). Psicodinâmica do trabalho: teoria, método e pesquisas. São Paulo: All Books Casa do Psicólogo, 2007. p. 66-86.

MARQUI. A. C.; GUIRRO. A.B.; MERLO. E.M. Vantagens decorrente da formação de associações de compra: um estudo de caso. REA - Revista Eletrônica da Administração, v. 3, n. 2, p. 1-11, 2004.

MINAYO, M. C. S. O desafio do conhecimento. 9. ed. São Paulo: Hucitec, 2006.

MINTZBERG, H. et al. O processo da estratégia: conceitos, contextos e casos selecionados. 4. ed. Porto Alegre: Bookeman, 2007.

MINTZBERG, H.; QUINN, J. B. O Processo da Estratégia. 3. ed. Porto Alegre: Bookman, 2001.

MINTZBERG, H.; AHLSTRAND, B.; LAMPEL, J. Safári de Estratégia: um roteiro pela selva do planejamento estratégico. 2. ed. São Paulo: Sênior, 2009.

NOHRIA, N. Is a network perspective a useful way of studying organizations? In: NOHRIA, Nitin; ECCLES, Robert G. Networks and organizations: structure, form, and action. Cambridge: Harvard University Press, 1992, p.1-22.

OLIVEIRA, D. P. R. Estratégia Empresarial e Vantagem Competitiva. 8. ed. São Paulo: Atlas, 2012.

OLIVEIRA, L. A estratégia Organizacional na competitividade: um estudo teórico. READ - Revista Eletrônica de Administração, v. 10, n. 4, p. 1-23, 2004.

PIRES, A. P. Amostragem e pesquisa qualitativa: ensaio teórico e metodológico. In: POUPART, Jean et al. A pesquisa qualitativa: enfoques epistemológicos e metodológicos. Petrópolis: Vozes, 2008. p.154-201.

PORTER, M. E. Vantagem Competitiva: criando e sustentando um desempenho superior. Rio de Janeiro: Elsevier, 1989. 
ROYER, R. As estratégias competitivas genéricas de Porter e o novo paradigma da customização em massa. In: ENCONTRO NACIONAL DE ENGENHARIA DE PRODUÇÃO, 30., 2010, São Carlos. Anais... São Carlos, SP: ANPAD, 2010, p. 1-14

SCHMITT, V. G. H; MORETTO NETO, L. Associativismo, comércio justo e desenvolvimento territorial sustentável: a experiência da toca tapetes. REGE Revista de Gestão, São Paulo, n. 3, p. 323-333, jul. 2011.

SEBRAE. Conheça o processo básico para se formar uma associação e quais as etapas. Disponível em: <http://www.sebrae.com.br/sites/PortalSebrae/artigos>. Acesso: 24 nov. 2016.

SILVA, P. M. Abordagem multinível em redes: Análise da produção científica. R. Adm. FACES Journal, Belo Horizonte, v. 14, n. 1, p. 141-151, jan./mar. 2015.

SILVA. E. L.O; BARROS. A.S.; CLARO. J. A. C.S. A vantagem competitiva dos pequenos varejistas de material para construção diante de grandes empresas do setor. Revista da Micro e Pequenas Empresas, Campo Limpo Paulista, v. 8, n. 1, p. 32-51, 2014.

SOUSA, G. H. B.; LEONE, R. J. G. O associativismo no setor supermercadista: um estudo de caso da formação de uma rede de pequeno varejista em Mossoró/RN. Revista Estratégia e Negócio, Florianópolis, n. 2, p. 89-117, 2010.

TAUHATA, T. L.; MACEDO-SOARES, T.D. Redes e alianças estratégicas no Brasil: caso cvrd. RAE-eletrônica, v. 3, n. 1, art. 4, jan./jun. 2004.

THORELLI, Hans B. Networks: between markets and hierarchies. Strategic Management Journal,Chichester, v. 7, n. 1, p. 37-51, jan. 1986.

VERSCHOORE, Jorge Renato S. (Org.). Redes de Cooperação: uma nova organização de pequenas e médias empresas no Rio Grande do Sul. Porto Alegre: FEE, 2004.

VERGARA, S. C. Projetos e relatórios de pesquisa em Administração. 15. ed. São Paulo: Atlas, 2014.

XAVIER, M. B.; ANDION, C. Análise comparada do associativismo e cooperativismo no Brasil e na Espanha: correntes predominantes, história e configuração jurídica. In: ENCONTRO DE ADMINISTRAÇÃO PÚBLICA E GOVERNANÇA DA ANPAD, 4., 2010, Vitória. Anais... Vitória, ES: ANPAD, 2010. p.1-14.

WINCKLER, N. C.; MOLINARI, G. T. Competição, Colaboração, Cooperação e Coopetição: Revendo os Conceitos em Estratégias Interorganizacionais. Revista ADMpg Gestão Estratégica, v. 4, n. 1, p. 1-12, 2011. 